\title{
Pertactin-deficient Bordetella pertussis isolates: evidence of increased circulation in Europe, 1998 to 2015
}

Alex-Mikael Barkoff', Jussi Mertsola², Denis Pierard³, Tine Dalby4, Silje Vermedal Hoegh', Sophie Guillot ${ }^{6}$, Paola Stefanelli7, Marjolein van Gent8, Guy Berbers ${ }^{8}$, Didrik Vestrheim9, Margrethe Greve-Isdahl9, Lena Wehlin ${ }^{10}$, Margaretha Ljungman ${ }^{10}$, Norman

K. Fry' ${ }^{11}$, Kevin Markey ${ }^{12}$, Qiushui He $\mathrm{He}^{1,13}$

1. Institute of Biomedicine, Department of Microbiology, Virology and Immunology, University of Turku, Turku, Finland

2. Department of Pediatrics and Adolescent Medicine, Turku University Hospital, Turku, Finland

3. Department of Microbiology, Universitair Ziekenhuis Brussel (UZ Brussel), Vrije Universiteit Brussel (VUB), Brussels, Belgium

4. Statens Serum Institut, Infectious Disease Preparedness - Bacteria, Parasites and Fungi, Copenhagen, Denmark

5. Department of Clinical Microbiology, Odense, University Hospital, Odense, Denmark

6. Institut Pasteur, Centre National de Référence de la Coqueluche et autres Bordetelloses, Paris, France

7. Department of Infectious Diseases, Istituto Superiore di Sanità, Rome, Italy

8. Centre for Infectious Disease Control, National Institute for Public Health and the Environment (RIVM), Bilthoven, the Netherlands

9. Department of Vaccine Preventable Diseases, Norwegian Institute of Public Health, Oslo, Norway

10. Department of Microbiology, Public Health Agency of Sweden, Solna, Sweden

11. Respiratory and Vaccine Preventable Bacteria Reference Unit, Public Health England - National Infection Service, London, United Kingdom

12. National Institute for Biological Standards and Control, Potters Bar, United Kingdom

13. Department of Medical Microbiology, Capital Medical University, Beijing, China

Correspondence: Qiushui He (qiushui.he@utu.fi)

Citation style for this article:

Barkoff Alex-Mikael, Mertsola Jussi, Pierard Denis, Dalby Tine, Hoegh Silje Vermedal, Guillot Sophie, Stefanelli Paola, van Gent Marjolein, Berbers Guy, Vestrheim Didrik, Greve-Isdahl Margrethe, Wehlin Lena, Ljungman Margaretha, Fry Norman K., Markey Kevin, He Qiushui. Pertactin-deficient Bordetella pertussis isolate: evidence of increased circulation in Europe, 1998 to 2015. Euro Surveill. 2019;24(7):pii=1700832. https://doi.org/10.2807/1560-7917.ES.2019.24.7.1700832

Introduction: Pertussis outbreaks have occurred in several industrialised countries using acellular pertussis vaccines (ACVs) since the 1990s. High prevalence of pertactin (PRN)-deficient Bordetella pertussis isolates has been found in these countries. Aims: To evaluate in Europe: (i) whether proportions of PRN-deficient strains increased in consecutive collections of $B$. pertussis clinical isolates; (ii) if the frequency of PRN-deficient strains in countries correlated with the time since ACV introduction; (iii) the presence of pertussis toxin (PT)-, filamentous haemagglutinin (FHA)- or fimbriae (Fim)-deficient isolates. Methods: $B$. pertussis clinical isolates were obtained from different European countries during four periods (EUpert I-IV studies): 1998 to 2001 $(n=102), 2004$ to $2005(n=154), 2007$ to $2009(n=140)$ and 2012 to $2015(n=265)$. The isolates' selection criteria remained unchanged in all periods. PRN, PT, FHA and Fim2 and Fim3 expression were assessed by ELISA. Results: In each period $1.0 \%$ (1/102), $1.9 \%$ (3/154), 6.4\% (9/140) and $24.9 \%(66 / 265)$ of isolates were PRN-deficient. In EUpert IV, PRN-deficient isolates occurred in all countries sampled and in six countries their frequency was higher than in EUpert III (for Sweden and the United Kingdom, p<0.0001 and $p=0.0155$, respectively). Sweden and Italy which used ACVs since the mid 1990s had the highest frequencies (69\%; $20 / 29$ and $55 \% ; 11 / 20$, respectively) while Finland, where primary immunisations with ACV containing PRN dated from 2009 had the lowest (3.6\%). Throughout the study, no PT- or FHA-deficient isolate and one Fim2/3-deficient was detected. Conclusion: Results suggest that the longer the period since the introduction of ACVs containing PRN, the higher the frequency of circulating PRN-deficient isolates.

\section{Introduction}

Between 2010 and 2012, nationwide pertussis outbreaks occurred in many countries including Australia, the Netherlands, the United Kingdom (UK) and the United States (US). In all of these countries acellular pertussis vaccines (ACVs) had been introduced for booster or primary immunisations in the late 1990 s or the early 2000 [ [1-4]. Currently used ACVs contain different combinations of pertussis toxin (PT), pertactin (PRN), filamentous haemagglutinin (FHA), and fimbriae 2 and 3 (Fim2/3) [5].

The genetic characteristics of Bordetella pertussis circulating strains have been investigated in relation to pertussis vaccine components [6]. It seems that after the introduction of ACVs, isolates not expressing the vaccine antigen PRN have appeared. $B$. pertussis PRN-deficient strains can cause typical symptoms of pertussis $[7,8]$. To date, isolates with these strains have been found in several countries, including Australia, Finland, France and the US [7-12]. PRN-deficient isolates have been increasingly reported 
and during the epidemics in 2010-12 the prevalence observed was high in the US (85\%) and Australia (78\%) $[8,13]$. Furthermore, since 2009, B. pertussis not expressing FHA nor PT and PRN was reported in France, Sweden and the US [14-16].

In Europe, vaccines and vaccination programmes vary in different countries [17]. To study genetic changes in $B$. pertussis populations in Europe, panels of $B$. pertussis isolates have been serially collected during four periods in a total of 11 European countries. The EUpert I panel was collected during 1999-2001 and included 102 isolates from five countries (Finland, France, Germany, the Netherlands and Sweden), the EUpert II in 2004-05 included 154 isolates from eight countries (Denmark, Finland, France, Germany, The Netherlands, Poland, Sweden and the UK), and the EUpert III in 2007-09 included 140 isolates from seven countries (Denmark, Finland, France, the Netherlands, Norway, Sweden and the UK). Four countries (Finland, France, the Netherlands, and Sweden) participated in all collections $[12,18,19]$. In the current study, the EUpert IV panel was collected from nine European countries: Belgium, Denmark, Finland, France, Italy, the Netherlands, Norway, Sweden, and the UK, during 2012-15 (time period was defined in the study contract). Altogether, 265 B. pertussis isolates were included. Selection criteria have remained unchanged for all four collections, which allows a unique opportunity to study and compare changes in bacterial populations over the past 15 years. Detailed vaccination programmes and vaccination coverage of the EUpert IV study countries are presented in Table $1[2,4,9,17,20]$. Vaccination programmes for the two countries (Germany, Poland) previously participating in EUpert studies have been published [19].

\section{Methods}

Study context and isolate panels

The total material comprised $661 \mathrm{~B}$. pertussis isolates, which were collected during the four study periods (EUpert I-IV) from 1998 to 2015. The genotyping results of EUpert I-III studies have been previously published $[12,18,19]$. In addition, data relating to the expression (serotyping) of Fim2/3 for EUpert I-III collections have also been published (no Fim2/3-deficient isolates found), as well as PRN expression data of the EUpert III collection, showing PRN-negative isolates in France, Norway and Sweden $[18,19]$.

In this study, the data from EUpert I-III were completed, by screening for PRN expression in EUpert I and II panels $(n=256)$. Moreover, FHA expression in EUpert I, II and III panels $(n=396)$ was tested (country-based data not shown).

The study also included the full analysis of EUpert IV isolates ( $n=265$ isolates), which were investigated for the presence of PT, FHA, PRN and Fim2 and Fim3.
Selection criteria for isolates and collection of patient data

The recommended number of isolates was 30 per country and the selection criteria for isolates in the EUpert IV study were the same as those used in the previous EUpert I-III studies [19].

These were as follows:

(i) B. pertussis isolates should be selected from different geographical regions in a given country and be epidemiologically unrelated.

(ii) An equal number of isolates from vaccinated $(n=15)$ and unvaccinated individuals $(n=15)$ should be collected. Isolates are preferred to be selected from individuals younger than 5 years of age.

(iii) For those countries with large numbers of isolates in their collections, isolates should be randomly selected in addition to the above criteria.

The following numbers of isolates were received per country: Belgium $(n=38)$, Denmark $(n=27)$, Finland $(n=28)$, France $(n=29)$, Italy $(n=20)$, the Netherlands $(n=32)$, Norway $(n=32)$, Sweden $(n=29)$, and the UK $(n=30)$. For Italy, all isolates were collected from the Rome area as no other isolates were available.

Data collection included original code of isolate, country, date of collection, city and available characteristics of patients. The latter included sex, age, vaccination status, number of doses received and hospitalisations due to pertussis.

\section{Culture}

$B$. pertussis isolates were shipped in frozen storage tubes to the University of Turku (UTU), Finland. Isolates were cultured on Regan-Lowe medium (without cephalexin) at $+35^{\circ} \mathrm{C}$ for $48 \mathrm{~h}$ to determine production of PRN, FHA, Fim2 and Fim3. To determine production of $\mathrm{PT}$, isolates were cultured at $+35^{\circ} \mathrm{C}$ with $5 \% \mathrm{CO}_{2}$ for $48 \mathrm{~h}$ [21]. The subculture of each isolate was kept minimal, although the exact number of subculture is not known.

\section{Detection of antigen expression}

Detection of PRN, PT, FHA and Fim2 and Fim3 expression was performed by specific enzyme-linked immunosorbent assay (ELISA) as described previously $[7,21,22]$. In the ELISA, whole bacterial cells were used as coating antigen. Production of different antigens (PT, FHA, PRN, Fim2 and Fim3) was detected with specific monoclonal antibodies, kindly provided by the National Institute for Biological Standards and Control (NIBSC) in the UK and the National Institute for Public Health and the Environment (RIVM) in the Netherlands. Three French strains including FR3496 (negative for PT), FR3693 (negative for PRN), and FR4624 (negative for FHA), as well as two Swedish Fim2- or Fim3-expressing strains S1 (Fim2) and S3 (Fim3) were used as controls. 
TABLE 1 A

Vaccination programmes with a focus on pertussis in nine European countries until 2015

\begin{tabular}{|c|c|c|c|c|c|}
\hline Country & $\begin{array}{l}\text { Start of } \\
\text { vaccination } \\
\text { against } \\
\text { pertussis }\end{array}$ & Initial (primary) & Booster & PRN included & $\begin{array}{c}\text { Approximate } \\
\text { coverage } \\
\text { (primary, \%) }\end{array}$ \\
\hline \multirow{3}{*}{ Belgium } & $1950 \mathrm{~S}$ & $2,3,4$ mo DtwP & No booster & NA & NA \\
\hline & 1999 (Flanders) & $\begin{array}{l}2,3,4 \text { mo } \\
\text { DTaP-IPV-Hib }\end{array}$ & $15 \mathrm{mo}, 4-6 \mathrm{yr}$ and $14-16 \mathrm{yr}$, DTaP-IPV-Hib & Yes & $97-99$ \\
\hline & 2002 (Wallonia) & $\begin{array}{l}2,3,4 \text { mo } \\
\text { DTaP-IPV-Hib }\end{array}$ & $15 \mathrm{mo}, 4-6 \mathrm{yr}$ and $14-16 \mathrm{yr}$, DTaP-IPV-Hib & Yes & $97-99$ \\
\hline \multirow{6}{*}{ Denmark } & 1961 & $\begin{array}{l}\text { 5, 6, 7, } 15 \mathrm{mo} \\
\text { DTwP }\end{array}$ & No booster & NA & 80 \\
\hline & 1969 & $\begin{array}{l}5,9 \text { wk and } 10 \\
\text { mo, wP }\end{array}$ & No booster & NA & 80 \\
\hline & 1997 & $\begin{array}{l}\text { 3, 5, } 12 \text { mo, } \\
\text { DTaP-IPV }\end{array}$ & No booster & No (solely PT) & 85 \\
\hline & 2002 & $\begin{array}{l}\text { 3, 5, } 12 \mathrm{mo} \\
\text { DTaP-IPV/Hib }\end{array}$ & No booster & No (solely PT) & 85 \\
\hline & 2003 & $\begin{array}{l}3,5,12 \mathrm{mo} \\
\text { DTaP-IPV/Hib }\end{array}$ & $5 \mathrm{yr}, \mathrm{dTap}$ & No (solely PT) & $85 / 85 a$ \\
\hline & 2004 & $\begin{array}{l}\text { 3, 5, } 12 \mathrm{mo} \\
\text { DTaP-IPV/Hib }\end{array}$ & 5 yr, dTap-IPV & No (solely PT) & $90 / 85 a$ \\
\hline \multirow{4}{*}{ Finland } & 1952 & 3, 4, 5 mo, DTwP & 20-24 mo, DTwP & NA & 95 \\
\hline & 2003 & 3, 4, 5 mo, DTwP & 20-24 mo, DTwP, and 6 yr, dtap & Yes (6 yr booster) & $95-99$ \\
\hline & 2005 & $\begin{array}{l}\text { 3, 4, } 12 \mathrm{mo} \\
\text { DTaP-IPV-Hib }\end{array}$ & 4 yr, DTaP-IPV-Hib, and 14 yr, dtap & No & $95-99$ \\
\hline & 2009 & $\begin{array}{l}3,5,12 \mathrm{mo} \\
\text { DTaP-IPV-Hib }\end{array}$ & 4 yr, DTaP-IPV, 14-15 yr dtap & Yes & $95-99$ \\
\hline \multirow{6}{*}{ France } & 1959 & $\begin{array}{l}\text { 3, 4, } 5 \mathrm{mo} \\
\text { DTwP-IPV }\end{array}$ & 16-18 mo, DTwP-IPV & NA & NA \\
\hline & 1995 & $\begin{array}{l}2,3,4 \mathrm{mo} \\
\text { DTwP-IPV-Hib }\end{array}$ & 16-18 mo, DTwP-IPV-Hib & NA & $>90 / 82^{a}$ \\
\hline & 1998 & $\begin{array}{l}\text { 2, 3, } 4 \mathrm{mo} \\
\text { DTwP-IPV-Hib }\end{array}$ & 16-18 mo, DTaP-IPV-Hib; 11-13 yr, DTaP-IPV & Yes (in boosters) & $>90 / 89^{a}$ \\
\hline & 2004 & $\begin{array}{l}\text { 2, 3, } 4 \mathrm{mo} \\
\text { DTaP-IPV-Hib }\end{array}$ & $\begin{array}{c}\text { 16-18 mo, DTaP-IPV-Hib; 11-13 yr, DTaP-IPV; } \\
\text { cocooning strategy, dTap-IPV }\end{array}$ & $\begin{array}{l}\text { Yes/no (two } \\
\text { vaccines) }\end{array}$ & $>90$ \\
\hline & 2008 & $\begin{array}{l}\text { 2, 3, } 4 \text { mo, } \\
\text { DTaP-IPV-Hib }\end{array}$ & $\begin{array}{l}\text { 16-18 mo, DTaP-IPV-Hib; } 11-13 \text { yr, DTaP-IPV; } \\
26-27 \text { yr, dTap-IPV cocooning strategy, dTap- } \\
\text { IPV, for all adults who did not receive booster } \\
\text { in last } 10 \text { yrs }\end{array}$ & $\begin{array}{l}\text { Yes/no (two } \\
\text { vaccines) }\end{array}$ & $>90$ \\
\hline & 2013 & $\begin{array}{l}\text { 2, 4,11 mo, } \\
\text { DTaP-IPV-Hib }\end{array}$ & $\begin{array}{c}6 \text { yr, DTaP-IPV-Hib; } 11-13 \text { yr, dTap-IPV; } 25 \mathrm{yr} \text {, } \\
\text { dTap-IPV cocooning strategy, dTap-IPV, for } \\
\text { all adults who did not receive booster in last } \\
5 \text { yrs }\end{array}$ & $\begin{array}{l}\text { Yes/no (two } \\
\text { vaccines) }\end{array}$ & $>90$ \\
\hline \multirow{3}{*}{ Italy } & 1961 & 2, 4, 6 mo DTwP & No booster & NA & 33 \\
\hline & 1995 & $\begin{array}{l}\text { 3, 5-6, 11-13 mo, } \\
\text { DTaP-IPV-Hib }\end{array}$ & $\begin{array}{c}\text { 5-6 yr and } 11-18 \text { yr (10 yr after primary aP), } \\
\text { DTaP-IPV }\end{array}$ & Yes & $>87$ \\
\hline & 2002 & $\begin{array}{l}\text { 3, 5-6, 11-13 mo, } \\
\text { DTaP-IPV-Hib }\end{array}$ & $\begin{array}{c}\text { 5-6 yr and } 11-18 \text { yr (10 yr after primary aP), } \\
\text { DTaP-IPV }\end{array}$ & Yes & $>95$ \\
\hline
\end{tabular}

DTaP: diphtheria-tetanus-acellular pertussis; dTap: diphtheria-tetanus-acellular pertussis (with reduced amount of diphtheria and pertussis antigens); dtap: diphtheria-tetanus-acellular pertussis (with reduced amount of diphtheria, tetanus and pertussis antigens); DTwP: diphtheria-tetanus-whole-cell pertussis; FHA: filamentous haemagglutinin; Hib: Haemophilus influenzae type b; IPV: inactivated poliovirus vaccine; mo: month; NA: not available; PRN: pertactin; PT: pertussis toxin; yr: year.

a Primary/booster vaccination.

DTaP vaccines contain 1-3 pertussis components: (i) PT, (ii) PT and FHA or (iii) PT, FHA and PRN. 
TABLE 1B

Vaccination programmes with a focus on pertussis in nine European countries until 2015

\begin{tabular}{|c|c|c|c|c|c|}
\hline Country & $\begin{array}{c}\text { Start of } \\
\text { vaccination } \\
\text { against } \\
\text { pertussis }\end{array}$ & Initial (primary) & Booster & PRN included & $\begin{array}{c}\text { Approximate } \\
\text { coverage } \\
\text { (primary, \%) }\end{array}$ \\
\hline \multirow{7}{*}{ Netherlands } & 1953 & 3, 4, $5 \mathrm{mo}$, DTwP & $4 \mathrm{yr}$, DTwP & NA & NA \\
\hline & 1962 & $\begin{array}{l}\text { 3, 4, 5, } 11 \mathrm{mo} \\
\text { DTwP-IPV }\end{array}$ & No booster & NA & NA \\
\hline & 1993 & $\begin{array}{l}3,4,5,11 \mathrm{mo} \\
\text { DTwP-IPV }\end{array}$ & No booster & NA & NA \\
\hline & 1999 & $\begin{array}{l}\text { 2, 3, 4, } 11 \mathrm{mo} \\
\text { DTwP-IPV }\end{array}$ & No booster & NA & 97 \\
\hline & 2001 & $\begin{array}{l}\text { 2, 3, 4, } 11 \mathrm{mo} \\
\text { DTwP-IPV }\end{array}$ & 4 yr, DTaP-IPV & Yes (in booster) & 97 \\
\hline & 2003 & $\begin{array}{l}\text { 2, 3, 4, } 11 \mathrm{mo}, \\
\text { DTwP-IPV-Hib }\end{array}$ & $4 \mathrm{yr}, \mathrm{DTaP}$ & Yes (in booster) & 97 \\
\hline & 2005 & $\begin{array}{l}\text { 2, 3, 4, } 11 \mathrm{mo} \\
\text { DTaP-IPV-Hib }\end{array}$ & 4 yr, DTaP-IPV & Yes & 97 \\
\hline \multirow{5}{*}{ Norway } & $1952-1984$ & $\begin{array}{l}\text { 3, 4, 5, 15-18 mo, } \\
\text { DTwP }\end{array}$ & No booster & NA & NA \\
\hline & $1984-1997$ & $3,5,10 \mathrm{mo}, \mathrm{DTwP}$ & No booster & NA & NA \\
\hline & 1998 & $3,5,12 \mathrm{mo}, \mathrm{DTaP}$ & No booster & Yes & 92 \\
\hline & 2001 & $\begin{array}{l}\text { 3,5, } 12 \mathrm{mo} \\
\text { DTaP-IPV + Hib }\end{array}$ & No booster & Yes & 91 \\
\hline & 2006 & $\begin{array}{l}\text { 3, 5, } 12 \text { mo, DTaP- } \\
\text { IPV or Hib }\end{array}$ & 7 yr, DTaP-IPV & Yes & 94 \\
\hline \multirow{6}{*}{ Sweden } & 1953 & $3,5,12 \mathrm{mo}, \mathrm{DTwP}$ & NA & NA & NA \\
\hline & $1979-1996$ & $\begin{array}{l}\text { No vaccination } \\
\text { against pertussis }\end{array}$ & NA & NA & NA \\
\hline & 1996 & $3,5,12 \mathrm{mo}, \mathrm{DTaP}$ & NA & Yes & 98 \\
\hline & 1998 & $\begin{array}{l}\text { 3, 5, 12 mo, } \\
\text { DTaP-IPV-Hib }\end{array}$ & NA & Yes & 98 \\
\hline & 2005 & $\begin{array}{l}\text { 3, 5, } 12 \mathrm{mo} \\
\text { DTaP-IPV-Hib }\end{array}$ & $10 \mathrm{yr}$, DTaP, for those born $1996-2001$ & $\begin{array}{l}\text { Not consistent, } \\
\text { PRN has not been } \\
\text { a component in } \\
\text { all vaccines used, } \\
\text { whereas PT and } \\
\text { FHA have }\end{array}$ & 98 \\
\hline & 2007 & $\begin{array}{l}\text { 3, 5, } 12 \mathrm{mo} \\
\text { DTaP-IPV-Hib }\end{array}$ & $\begin{array}{l}\text { 5-6 yr, DTaP-IPV, for those born 2002; 14-16 } \\
\text { yr, dTap }\end{array}$ & NA & 98 \\
\hline \multirow{6}{*}{$\begin{array}{l}\text { United } \\
\text { Kingdom }\end{array}$} & 1957 & $\begin{array}{l}\text { DTwP completed } \\
\text { by } 6 \text { mo }\end{array}$ & NA & NA & NA \\
\hline & 1968 & 3, 5, $11 \mathrm{mo}, \mathrm{DTwP}$ & NA & NA & NA \\
\hline & 1990 & 2, 3, 4 mo, DTwP & NA & NA & $>90$ \\
\hline & $2000-2001$ & 2, 3, 4 mo, DTwP & 4-6 yr, DTaP-Hib & Yes (in booster) & 94 \\
\hline & 2004 & $\begin{array}{l}\text { 2, 3, } 4 \mathrm{mo} \\
\text { DTaP-IPV-Hib }\end{array}$ & $4-6$ yr, DTaP-Hib & Yes & 94 \\
\hline & 2012 & $\begin{array}{l}\text { 2, 3, } 4 \text { mo, } \\
\text { DTap-IPV-Hib }\end{array}$ & $\begin{array}{c}3 \text { yr } 4 \text { mo, DTaP-Hib + recommended maternal } \\
\text { vaccination }\end{array}$ & Yes & 94 \\
\hline
\end{tabular}

DTaP: diphtheria-tetanus-acellular pertussis; dTap: diphtheria-tetanus-acellular pertussis (with reduced amount of diphtheria and pertussis antigens); dtap: diphtheria-tetanus-acellular pertussis (with reduced amount of diphtheria, tetanus and pertussis antigens); DTwP: diphtheria-tetanus-whole-cell pertussis; FHA: filamentous haemagglutinin; Hib: Haemophilus influenzae type b; IPV: inactivated poliovirus vaccine; mo: month; NA: not available; PRN: pertactin; PT: pertussis toxin; yr: year.

DTaP vaccines contain 1-3 pertussis components: (i) PT, (ii) PT and FHA or (iii) PT, FHA and PRN. 
TABLE 2

Primers used in this study for PCR amplification and sequencing

\begin{tabular}{|c|c|c|}
\hline Name of primer & Sequence $\left(5^{\prime}-3^{\prime}\right)$ & Target (position on the genome) ${ }^{a}$ \\
\hline PrnG_A2 for & CCC ATT CTT CCC TGT TCC AT & $\begin{array}{c}\text { prn gene amplification \& sequencing, first part } \\
(1098027-1098046)\end{array}$ \\
\hline PrnG_A rev & TGT TGG CAA GGG TAA AGG TC & prn gene amplification, first part (1099698-1099717) \\
\hline Prn-BF_1322bp & AGC TGG GCG GTT CAA GGT & $\begin{array}{c}\text { prn gene amplification \& sequencing, second part } \\
(1099488-1099505)\end{array}$ \\
\hline PrnGeneR & GCC TGA GCC TGG AGA CTG G & prn gene amplification, second part (1100877-1100895) \\
\hline PrnProm FOR & GCT CAA AGC AGG AAA AAG CA & prn promoter amplification \& sequencing (1097635-1097654) \\
\hline PrnProm REW & CGCTTACCTTGATGGTGGTT & prn promoter amplification (1098288-1098307) \\
\hline PrnSeq1F & GCC AAT GTC ACG GTC CAA & prn gene amplification, sequencing (1098595-1098612) \\
\hline PrnSeq2F & TGT CGA TCA CCT TGC AGG & prn gene amplification, sequencing (1099166-1099183) \\
\hline PrnSeq3F & AAC GGC AAT GGG CAG TG & prn gene amplification, sequencing $(1099765-1099781)$ \\
\hline PrnSeq4F & GACAGCGGTTTCTACCTGGA & prn gene amplification, sequencing (1100269-1100288) \\
\hline
\end{tabular}

a Position based on the genome of Tohama I (GenBank accession number: NC 002929).

Sequencing of the whole prn gene

To investigate the mechanisms for PRN-deficiency of the EUpert IV collection, the prn gene was first amplified and sequenced afterwards. Only isolates with detected PRN-deficiency were sequenced. All primers are presented in Table 2. The method and some of the primers have been described previously $[12,23]$. Each reaction mixture was preheated for $5 \mathrm{~min}$ at $95^{\circ} \mathrm{C}$. Thirty amplification cycles were used with following programme: $95^{\circ} \mathrm{C}$ for $30 \mathrm{~s}, 59^{\circ} \mathrm{C}$ for $30 \mathrm{~s}$ and $90 \mathrm{~s}$ at $72^{\circ} \mathrm{C}$ followed by a final cycle at $72^{\circ} \mathrm{C}$ for $7 \mathrm{~min}$. Sequencing was performed at the Institute for Molecular Medicine Finland (FIMM) laboratory (Helsinki, Finland).

\section{Statistical analysis}

Fisher's exact and chi-squared tests to assess differences between vaccinated and unvaccinated patients and frequency of PRN-deficient isolates between EUpert I-IV collections were calculated using GraphPad prism 4.0 version (San Diego, California (CA), US). Two-tailed $p$ values $<0.05$ were considered significant. To analyse the trend in PRN-deficiency over time, the proportions of PRN-deficient isolates per country were estimated using logistic regression with the year of diphtheria-tetanus-acellular pertussis (DTaP, containing PRN) implementation in the country as the independent variable. Results were given as odds ratios (OR) between start of ACV and frequency of PRN-deficient isolates. The analysis was conducted using the R software ( $R$ foundation).

\section{Results}

\section{Pertactin expression}

In EUpert I, one $(1.0 \% ; 1 / 102$; Sweden $(n=1))$ PRNdeficient isolate was found. In EUpert II three (1.9\%; 3/154; France $(n=1)$, Germany $(n=1)$, the Netherlands $(\mathrm{n}=1))$ and in EUpert III nine $(6.4 \%$; $9 / 140$; France $(n=5)$, Norway $(n=3)$, Sweden $(n=1))$ such isolates were detected. In EUpert IV, 66 (24.9\%; 66/265) isolates were deficient for PRN (Figure 1). Significant increase of PRN-deficient isolates was found in EUpert IV compared with the three previous EUpert studies ( $p<0.0001$ ). Furthermore, PRN-deficient isolates were found in all nine study countries in different proportions as shown in Table 3. In five countries (Denmark, Finland, France, the Netherlands and Norway) frequency of PRN-deficient isolates seemed to have increased when compared to EUpert III, moreover in two (Sweden and the United Kingdom) the increase was significant ( $p<0.0001$ and $p=0.0155$, respectively). Among the PRN-deficient isolates, 56 (84.9\%) were Fim3, nine (13.6\%) Fim2 and one (1.5\%) Fim2,3 serotype.

The distribution of the PRN-deficient isolates and their frequencies in the EUpert IV-study countries is shown in Table 3 together with the year of introduction of ACVs. The highest frequencies of PRN-deficient isolates were found in Sweden (69.0\%), Italy (55.0\%), Norway (31.3\%) and the UK (26.7\%). The lowest numbers were found from Finland and the Netherlands ( $10 \%$ in both). The difference in frequencies between Sweden, Italy, Norway and the UK versus Finland were all significant (all p < 0.05), whereas for the Netherlands, a significant difference was only observed with Sweden and Italy (both $\mathrm{p}<0.001$ ). Figure 2 shows the proportion of PRNdeficient isolates observed in EUpert IV study and the implementation year of primary DTaP immunisation in all countries, except Denmark where DTaP vaccine containing only one pertussis antigen, PT, is used. Denmark is the only country in Europe using this vaccine. The correlation between year of introduction of ACV and PRN-deficient isolates in Denmark was however checked, and was lower than for most of the other countries (data not shown). For the other countries, an OR of 1.29 ( $95 \% \mathrm{Cl}: 1.18-1.41$ ) was found, meaning that every year after the introduction of DTaP vaccination the odds to have PRN-deficient strains increases with $29 \%$. 


\section{FIGURE 1}

Proportion of pertactin-deficient isolates in EUpert I-IV collections, Europe, 1998-2015 ( $\mathrm{n}=661$ isolates)

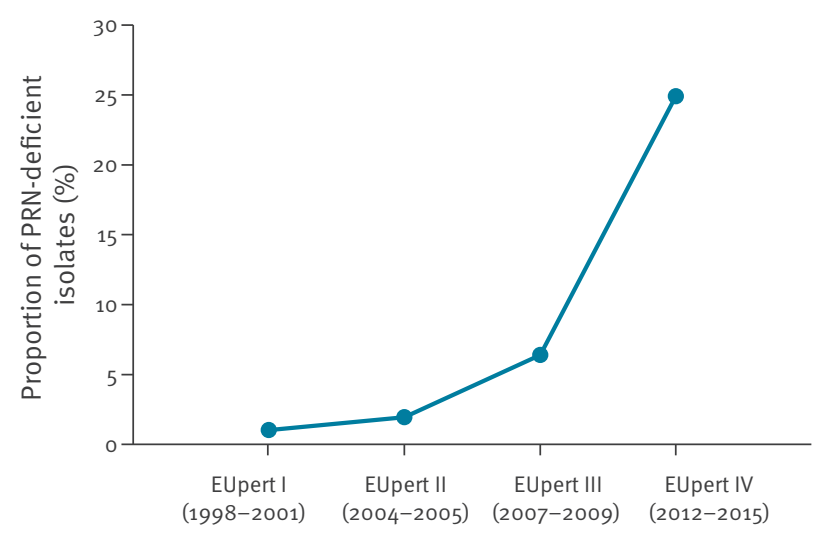

Collection of isolates

PRN: pertactin.

The number of isolates tested in the four periods was 102 in EUpert I (1998-2001), 154 in EUpert II (2004-2005), 140 in EUpert III (2007-2009) and 265 in EUpert IV (2012-2015) from 11 countries with distinct vaccines and vaccination strategies.

\section{Molecular mechanisms causing pertactin deficiency}

The entire prn gene was sequenced. We found six different mechanisms causing PRN expression to be suppressed (Table 4). Of the 66 PRN-deficient isolates, $31(47.0 \%)$ had the insertion of the IS481 element at position $1613^{\wedge} 1614$ (from the beginning of the prn gene) either in forward or reverse orientation and one had it at position $2735^{\wedge} 2736$. IS481 element is found in multiple copies in the genome of $B$. pertussis and helps it to adapt to different immunised populations [24]. The second common cause (18 isolates; $27.3 \%$ ) was a large inversion in the prn promoter area. In one isolate, a nucleotide mutation of a $G$ to a $T$ at position 2077 leading to a stop codon, which was not previously described, was found. Other causes were single point mutation and deletion, and deletion of the entire prn gene. In addition, the mechanism behind PRN-deficiency for one isolate was not located within the prn gene, although repeated sequencing was performed.

\section{Pertactin deficiency, vaccination status and patient data}

Of 265 patients in the EUpert IV study, 130 (49.1\%) were vaccinated and 135 (50.9\%) unvaccinated. PRNdeficient isolates were isolated from 66 patients. Of them, $16(24.2 \%)$ were partially vaccinated, 10 $(15.2 \%)$ had received full primary vaccination, six (9.1\%) had full primary and booster vaccination, 32 $(48.5 \%)$ were unvaccinated and for two patients $(3.0 \%)$ the vaccination status was unknown. No significant difference in proportion of PRN-deficient isolates was found between vaccinated and unvaccinated patients among study countries, except in the UK where these isolates were found more in vaccinated patients $(p=0.0348)$. PRN-deficient isolates were found mostly from infants less than one year of age (39/66; $59.1 \%$ ), but the age ranged from $<1$ month to 55 years. Hospitalisation data were available only for 41 patients and showed a range from o to 28 days. Complications data were only available for 11 patients with one having thrombocytopenia and one bradycardia and hypoxia, for the rest no severe complications were notified. From these patients, only one was vaccinated.

\section{Pertussis toxin, filamentous haemagglutinin} and fimbrial expression

Among isolates collected during the four studies $(n=661)$, one $(0.15 \%)$ did not produce Fim2 or Fim3. This isolate was found in Norway and originated from the EUpert IV collection. No difference in bacterial growth and colony formation on charcoal agar was noticed between Fim-positive and -negative isolates. In the EUpert IV study, 120 (45.3\%), 141 (53.2\%) and three (1.1\%) isolates carried Fim2, Fim3 and Fim2,3 serotypes, respectively. No other Fim-deficient isolate was found.

No FHA-deficient isolates were found among EUpert I-IV collections. No PT-deficient isolates were found among the EUpert IV collection.

\section{Discussion}

In this study, serial collections of $B$. pertussis isolates were investigated from 1998 to 2015 in European countries where different vaccines and vaccination strategies are used. The countries submitting isolates varied between collections, however Finland, France, the Netherlands and Sweden contributed to all of them $[12,18,19]$. In the latest collection, nine countries were included. The frequency of $B$. pertussis PRN-deficient isolates was low $(13 / 396 ; 3.2 \%)$ during the period 1998-2009 but this had increased in 2012-2015 with a prevalence of $24.9 \%$ (Figure 1 ). Our findings are in line with previous studies from the US and Australia, where the prevalence of PRN-deficient isolates has increased significantly during 2010-2012 [13,14].

The coverage for primary vaccination has been high since the introduction of ACVs in all study countries (>90\%), suggesting that there is a selective pressure for $B$. pertussis to inactivate the PRN-production. It is known that population density plays a role in transmission of bacterial pathogens. However, this does not seem to affect increased circulation of PRNdeficient isolates, because, although the Netherlands has a high population density, the frequency of PRNdeficient isolates has only increased slightly during the past 10 years. On the other hand both Sweden and Finland have low population densities, but significantly different frequencies of PRN-deficient isolates.

All study countries in the two last EUpert collections have implemented either ACV booster vaccination or changed to ACV primary vaccination in the 1990 s or 
Number of pertactin-deficient Bordetella pertussis isolates in study countries in the EUpert IV collection, Europe, 2012-2015 ( $\mathrm{n}=66$ isolates)

\begin{tabular}{|c|c|c|c|c|c|c|c|c|}
\hline Country & $\begin{array}{l}\text { Number of } \\
\text { PRN-deficient } \\
\text { isolates in } \\
\text { EUpert IV }\end{array}$ & $\begin{array}{l}\text { Number of } \\
\text { isolates } \\
\text { collected in } \\
\text { EUpert IV }\end{array}$ & $\begin{array}{c}\text { Frequency of } \\
\text { PRN-deficient } \\
\text { isolates (\%) in } \\
\text { EUpert IV (95\% } \\
\text { CI) }\end{array}$ & $\begin{array}{l}\text { Number } \\
\text { of PRN- } \\
\text { deficient } \\
\text { isolates in } \\
\text { EUpert III }\end{array}$ & $\begin{array}{l}\text { Number of } \\
\text { isolates } \\
\text { collected } \\
\text { in EUpert } \\
\text { III }\end{array}$ & $\begin{array}{l}\text { Frequency of } \\
\text { PRN-deficient } \\
\text { isolates (\%) in } \\
\text { EUpert III (95\% } \\
\text { CI) }\end{array}$ & $\begin{array}{l}\text { EUpert IV vs. } \\
\text { EUpert III ( } p \\
\text { value) }\end{array}$ & $\begin{array}{l}\text { Year of ACV } \\
\text { introduction } \\
\text { for primary } \\
\text { vaccination }\end{array}$ \\
\hline Sweden & 20 & 29 & $69.0(50.8-82.7)$ & 1 & 19 & $5.0(0.9-23.6)$ & $\begin{array}{c}<0.001 \\
\text { (increase) }\end{array}$ & 1996 \\
\hline Italy & 11 & 20 & $55.0(34.2-74.2)$ & NA & NA & NA & NA & 1995 \\
\hline Norway & 10 & 32 & $31.3(18.0-48.6)$ & 5 & 20 & $\begin{array}{c}25.0 \\
(11.2-46.9)\end{array}$ & 0.7574 & 1998 \\
\hline $\begin{array}{l}\text { United } \\
\text { Kingdom }\end{array}$ & 8 & 30 & $26.7(14.2-44 \cdot 5)$ & 0 & 20 & $0.0(0.0-16.1)$ & $\begin{array}{c}0.0155 \\
\text { (increase) }\end{array}$ & 2004 \\
\hline France & 5 & 29 & $17.2(7.6-34.6)$ & 3 & 20 & $15.0(5.2-36.0)$ & 1.0000 & 2004 \\
\hline Denmark & 4 & 27 & $14.8(5.9-32.5)$ & 0 & 23 & $0(0.0-14 \cdot 3)$ & 0.1147 & $1997^{\mathrm{b}}$ \\
\hline Belgium & 4 & 38 & $10.5(4.2-24.1)$ & NA & NA & NA & NA & $\begin{array}{c}1999 \text { (Flanders) / } \\
2002 \text { (Wallonia) }\end{array}$ \\
\hline Netherlands & 3 & 32 & $9.4(3.2-24.2)$ & 0 & 20 & $0(0.0-16.1)$ & 0.2760 & 2005 \\
\hline Finland & 1 & 28 & $3.6(0.6-17.7)$ & 0 & 16 & $0(0.0-19.4)$ & 1.0000 & $2005^{c}$ \\
\hline
\end{tabular}

ACV: acellular pertussis vaccine; Cl; confidence interval; FHA: filamentous haemagglutinin; NA: not available; PRN: pertactin; PT: pertussis toxin.

a The years in this column are given for the introduction of a PRN-containing ACV except if otherwise stated.

b In Denmark, solely PT-based vaccine in use from 1997.

' In Finland, vaccine containing PT and FHA was first used, and PRN was included in 2009.

at the beginning of 2000 (Tables 1 and 3) $[2,17,20]$. Therefore, we made a comparison between the introduction of ACV and the increase in PRN-deficient isolates. As shown in Figure 2, it appears that countries which introduced primary ACV vaccination earliest have a higher proportion PRN-deficient isolates in 2015 than those where primary ACV vaccination was introduced more recently. Sweden and Italy were the first two countries where ACVs were introduced in Europe and the proportions of PRN-deficient isolates in these countries $(69.0 \%$ and $55.0 \%)$ are significantly higher than other countries (Table 3). If we compare Finland and the Netherlands, both switched to ACV in 2005, but Finland used first ACV containing PT and FHA and started to use PRN in the three-component vaccine from 2009 (Table 1). This is reflected in the frequency of PRN-deficient isolates observed in the Netherlands (9.4\%) and in Finland (3.6\%). Our study supports the hypothesis that the emergence of PRNdeficient isolates is dependent on the timing since the introduction of ACV containing PRN.

In Europe, Poland is the only country using whole cell vaccines for primary vaccination. Unfortunately Polish isolates were not available in the latest EUpert III and IV studies. In EUpert II study, 13 isolates were available [25]. None was found to be PRN-deficient.

Our results showed that PRN-deficient isolates were also found in Denmark, where a monocomponent PT vaccine has been used more than 15 years [26]. This finding is very interesting as without PRN in the vaccine, there should not be a vaccine derived selection for PRN-deficient B. pertussis isolates. One possible explanation might be that the patients in Denmark were infected with PRN-deficient strains from other neighbouring countries like Sweden and Norway where the frequency of PRN-deficient isolates is high. Indeed, the four PRN-deficient isolates observed in Denmark were caused by three different mechanisms (Table 4), which also mediated PRN-deficiency in other countries. In addition, PRN-deficient isolates have shown to have positive advantage in causing disease in vaccinated population (diphtheria-tetanus-whole-cell pertussis or DTaP) [8]. A recent study in mice demonstrated that a PRN-deficient isolate colonised the respiratory tract more effectively than PRN-positive isolate in ACVimmunised mice [27]. It is possible that these isolates could have similar advantages in colonisation and disease development in human populations. Travel/ commute information could be collected in the future to show the possible effect on strain shifting from one country to another.

The correlation between year of introduction of ACV and PRN-deficient isolates was however lower for Denmark than for most of the other countries, except Belgium where PRN-containing ACV was introduced in Flanders and Wallonia in 1999 and 2002, respectively. According to Pierard (personal communication April, 2017) ca $60 \%$ of Belgian children (less than 17 years of age) received ACV in 1999 and $40 \%$ in 2002. This may explain the low frequency of PRN-deficient isolates found in Belgium in this study. 


\section{FIGURE 2}

Correlation between the introduction of a primary acellular pertussis vaccine containing pertactin (PRN) in a European country and the proportion of PRN-deficient isolates found in the study, 2012-2015

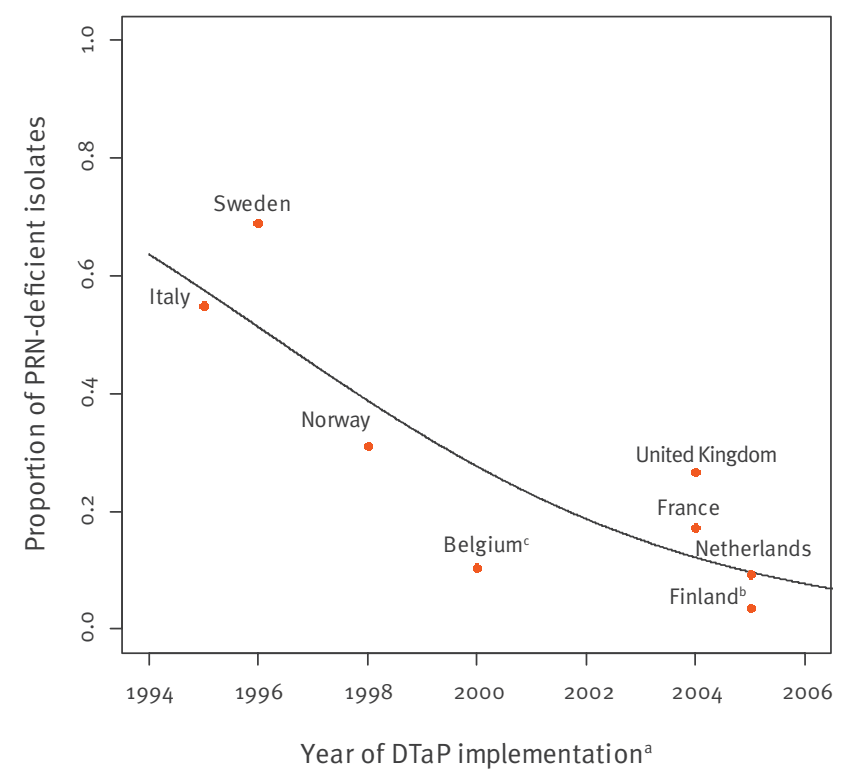

ACV: acellular pertussis vaccine; DTaP: diphtheria-tetanusacellular pertussis; FHA: filamentous haemagglutinin; PRN: pertactin; PT: pertussis toxin.

a Year when an ACV containing PRN was implemented for primary vaccination, except for Finland where the year of introduction of ACV not containing PRN is shown (see footnote b).

${ }^{b}$ In Finland, ACV containing PT and FHA was first used in 2005 and ACV containing PRN was introduced in 2009.

' In Belgium, ACV was introduced in 1999 in Flanders (representing $60 \%$ of the population) and in 2002 in Wallonia (representing $40 \%$ of the population); therefore, a balanced mean of introducing year (2000.2y) was used in calculations.

Denmark is not included in the figure, as a monocomponent PT vaccine is used in this country since 1997.

Previously, it has been reported that PRN-deficient isolates are more common in vaccinated than in unvaccinated individuals [8]. In this study we did not find such a difference. When we compared the vaccination data of patients with PRN-deficient isolates, the distribution between vaccinated and unvaccinated individuals was close to 1:1 (excluding the UK). This may suggest that PRN-deficient strains might be able to infect individuals regardless of vaccination status. This could also partly explain why the PRN-deficient isolates were found in Denmark. However, a further prospective study in which detailed clinical information of patients is collected would be needed to explore these hypotheses. It is also worth keeping in mind that the number of isolates isolated from vaccinated and unvaccinated individuals included in the present study was very limited and there might be a selection bias because of the high number of infants in our study.
In this study, seven different molecular mechanisms were found to mediate PRN deficiency for $B$. pertussis. Five mechanisms have been reported previously $[9,12,28]$. A new deletion of thymine in position $631^{\wedge} 632$ ( 4 isolates) and point mutation of $\mathrm{G}>\mathrm{T}$ in position 2077 ( 1 isolate) was found. In addition, the mechanism for one isolate was not located within the prn gene.

The appearance of PRN-deficient isolates was first described in Italy and France with only a few isolates in $2007[9,11]$. During the period of 2000-10, frequencies of PRN-deficient isolates started to increase and reached $5-8 \%$ prevalence in France, Australia and the US. ACVs were introduced in Australia and in the US in the late $1990 \mathrm{~s}[13,16,28]$. However, after 2010 the prevalence of PRN-deficient isolates had increased dramatically in Australia (78\%) and the US (85\%), whereas in France it increased slightly to $15 \%[8,13,29]$. In Japan ACV vaccination has been used since 1981 and the first detection of PRN-deficient isolates was reported in 2012 on isolates from 1995-1999. During the period 1990-1994 only eight (5\%) such isolates were detected, whereas the prevalence increased to $32-38 \%$ in 2000-2009 [30]. However, a recent report from Japan showed that frequency of PRN-deficient isolates decreased to $8 \%$ in 2014-2016. The authors reported that vaccines not including PRN have been introduced since 2012 and may have resulted in the low prevalence [31]. Results from all these studies are in line with our findings and suggest that number of PRNdeficient $B$. pertussis isolates is increasing constantly 10-15 years after the introduction of ACV vaccination containing PRN.

In this study we did not find any PT-deficient isolates, even from Denmark, although the selective pressure from the monocomponent PT vaccine is considered to be high. Moreover, only a few PT-deficient isolates have been reported previously $[9,14,16]$. This confirms that PT is important for $B$. pertussis and plays an essential role in pathogenesis of pertussis. However, the number of isolates from Denmark was limited so we cannot conclude that PT-deficient isolates are not present in Denmark. We did not detect any FHA-deficient isolates either. As FHA is dominant in adhesion and is needed for tracheal colonisation, it seems to be conserved in $B$. pertussis [5]. For fimbriae, only one isolate that did not express Fim2 or Fim3 was isolated in Norway in 2013. Previously, one study from Japan described a similar finding among Japanese isolates [32]. However, shifts from Fim2 to Fim3 or vice versa may be common among circulating isolates after epidemic seasons, so it is difficult to predict how the expression will change and whether the appearance of Fim2/3-deficient isolates will increase or not.

There are both strengths and limitations in this study. The strengths of this study are that (i) we have a serial collection of isolates during the past 15 years, (ii) selection criteria have been the same for all collections, (iii) we have isolates from countries with 
TABLE 4

Mechanisms causing pertactin deficiency in Bordetella pertussis isolates of the EUpert IV collection, Europe, 2012-2015 $(\mathrm{n}=66$ isolates $)$

\begin{tabular}{|c|c|c|c|c|c|c|c|c|c|c|c|}
\hline \multirow[b]{2}{*}{ Mechanism } & \multicolumn{9}{|c|}{ Country and number of isolates with a given mutation } & \multirow[b]{2}{*}{ Total } & \multirow[b]{2}{*}{$\%$} \\
\hline & Belgium & Denmark & Finland & France & Italy & Netherlands & Norway & Sweden & $\begin{array}{l}\text { United } \\
\text { Kingdom }\end{array}$ & & \\
\hline $\begin{array}{l}\text { Insertion of IS481 } \\
\text { element }\end{array}$ & 2 & 2 & 0 & 0 & 8 & 1 & 3 & 11 & 5 & 32 & 48.5 \\
\hline $\begin{array}{l}\text { Inversion of } 22 \mathrm{~kb} \\
\text { of prnpromoter }\end{array}$ & 2 & 0 & 0 & 5 & 1 & 2 & 0 & 7 & 1 & 18 & 27.3 \\
\hline 223STOP: $\mathrm{C}>\mathrm{T}$ & 0 & 0 & o & o & o & 0 & 6 & 1 & 1 & 8 & 12.1 \\
\hline $631^{\wedge} 632 \mathrm{STOP}: \Delta \mathrm{T}$ & 0 & 1 & 0 & 0 & 2 & 0 & 0 & 1 & 0 & 4 & 6.1 \\
\hline$\Delta$ prn & 0 & 1 & 0 & 0 & 0 & 0 & 1 & 0 & 0 & 2 & 3.0 \\
\hline 2077STOP: G > T & 0 & 0 & 1 & 0 & 0 & 0 & 0 & 0 & 0 & 1 & 1.5 \\
\hline Unknown & 0 & 0 & 0 & 0 & 0 & 0 & 0 & 0 & 1 & 1 & 1.5 \\
\hline Total & 4 & 4 & 1 & 5 & 11 & 3 & 10 & 20 & 8 & 66 & 100.0 \\
\hline
\end{tabular}

$\Delta$ : deletion; >: mutation; ^ : position of the insertion in the gene; prn: pertactin gene; STOP: stop codon in the gene.

different vaccination programmes and therefore, the impact of ACV introduction could be assessed, (iv) the place of origin is known for all isolates and shows that these isolates were not collected from local outbreaks and (v) all analyses were done by one laboratory with the same protocol so the results are comparable. The limitations included are as follows: (i) clinical information, including e.g. length of hospitalisation and severe complications were not available from many study patients (159 of 265), (ii) the number of isolates included from each country was very limited and not proportional to population size. However, they do comprise almost all isolates available in many countries such as Denmark, Finland and Italy, where the use of culture for diagnosis of pertussis is diminishing. For those countries with limited number of isolates, it would be beneficial if DNA from clinical specimens could be used directly for detection of PRNdeficient isolates e.g. through PCR and sequencing. (iii) The epidemiological pressure of pertussis varies in European countries which could have an effect on the spread of new emerging strains, like in Finland the incidence was continuously decreasing and was very low during the period of EUpert IV study [33].

In conclusion, the prevalence of PRN-deficient $B$. pertussis isolates has increased in Europe and the increase seems to be associated with the time since the introduction of ACVs. PRN-deficient isolates were found in all nine study countries during the latest collection and the isolates were isolated from both vaccinated and unvaccinated individuals. The highest number of these isolates was found in Sweden and Italy, which were the earliest adopters of ACV among the study countries. Our study also underscores the importance of longterm surveillance of $B$. pertussisantigen production because of its possible impact on the effectiveness of vaccines.

\section{Acknowledgements}

We thank Päivi Haaranen and Mari Virta for their great help in the laboratory work. Randi Føns Petersen, Kirsten Olsson and Lene Berthelsen for their help with strain collections.

Financial support: The EUpertstrain II, III and IV studies were jointly funded by GlaxoSmithKline Biologicals (GSK study identifier: 201328), Wavre, Belgium and Sanofi Pasteur MSD, Lyon, France. Both GlaxoSmithKline Biologicals SA and Sanofi Pasteur were provided the opportunity to review a preliminary version of this manuscript for factual accuracy but the authors are solely responsible for final content and interpretation. The study has been registered in ClinicalTrials.gov (Identifier: NCT03197597).

\section{Conflict of interest}

None declared.

Authors' contributions

Alex-Mikael Barkoff organized strain collection, performed laboratory work, analysed data and wrote manuscript; Jussi Mertsola designed the study and was involved in manuscript writing; Denis Pierard was involved in strain collection and manuscript writing; Tine Dalby was involved in strain collection and manuscript writing; Silje Vermedal Hoegh was involved in strain collection and manuscript writing; Sophie Guillot was involved in strain collection and manuscript writing; Paola Stefanelli was involved in strain collection and manuscript writing; Marjolein van Gent was involved in strain collection and manuscript writing ; Guy Berbers was involved in strain collection and manuscript writing; Didrik Vestrheim was involved in strain collection and manuscript writing; Margrethe Greve-Isdahl was involved in strain collection and manuscript writing; Lena Wehlin was involved in strain collection and manuscript writing; Margaretha Ljungman was involved in strain collection and manuscript writing; Norman K. Fry was involved in strain collection and 
manuscript writing; Kevin Markey was involved in strain collection and manuscript writing; Qiushui He designed the study, organized strain collection, analyzed the data and wrote the manuscript.

All authors contributed to the concept of the manuscript and reviewed it critically. All authors have read and approved the final manuscript. All authors fulfil ICMJE authorship criteria.

\section{References}

1. Campbell P, McIntyre P, Quinn H, Hueston L, Gilbert GL, McVernon J. Increased population prevalence of low pertussis toxin antibody levels in young children preceding a record pertussis epidemic in Australia. PLoS One. 2012;7(4):e35874. https://doi.org/10.1371/journal.pone.0035874 PMID: 22558249

2. Amirthalingam G, Gupta S, Campbell H. Pertussis immunisation and control in England and Wales, 1957 to 2012: a historical review. Euro Surveill. 2013;18(38):20587. https://doi.org/10.2807/1560-7917.ES2013.18.38.20587 PMID: 24084340

3. Winter K, Glaser C, Watt J, Harriman KCenters for Disease Control and Prevention (CDC). Pertussis epidemic--California, 2014. MMWR Morb Mortal Wkly Rep. 2014;63(48):1129-32. PMID: 25474033

4. van der Maas NA, Mooi FR, de Greeff SC, Berbers GA, Spaendonck MA, de Melker HE. Pertussis in the Netherlands, is the current vaccination strategy sufficient to reduce disease burden in young infants? Vaccine. 2013;31(41):4541-7. https:// doi.org/10.1016/j.vaccine.2013.07.060 PMID: 23933365

5. Kilgore PE, Salim AM, Zervos MJ, Schmitt HJ. Pertussis: Microbiology, Disease, Treatment, and Prevention. Clin Microbiol Rev. 2016;29(3):449-86. https://doi.org/10.1128/ CMR.00083-15 PMID: 27029594

6. Weigand MR, Peng Y, Loparev V, Batra D, Bowden KE, Burroughs M, et al. The History of Bordetella pertussis Genome Evolution Includes Structural Rearrangement. J Bacteriol. 2017;199(8):e00806-16. https://doi.org/10.1128/JB.00806-16 PMID: 28167525

7. Barkoff AM, Mertsola J, Guillot S, Guiso N, Berbers G, He Q. Appearance of Bordetella pertussis strains not expressing the vaccine antigen pertactin in Finland. Clin Vaccine Immunol. 2012;19(10):1703-4. https://doi.org/10.1128/CVI.00367-12 PMID: 22914363

8. Martin SW, Pawloski L, Williams M, Weening K, DeBolt C, Qin X, et al. Pertactin-negative Bordetella pertussis strains: evidence for a possible selective advantage. Clin Infect Dis. 2015;60(2):223-7. https://doi.org/10.1093/cid/ciu788 PMID: 25301209

9. Bouchez V, Brun D, Cantinelli T, Dore G, Njamkepo E, Guiso N. First report and detailed characterization of B. pertussis isolates not expressing Pertussis Toxin or Pertactin. Vaccine. 2009;27(43):6034-41. https://doi.org/10.1016/j. vaccine.2009.07.074 PMID: 19666155

10. Lam C, Octavia S, Ricafort L, Sintchneko V, Gilbert L, Wood N, et al. Emergence of pertactin deficient Bordetella pertussis in Australia is due to independent events. 10th Internationa Symposium on Bordetella; 2013 Sep 8-11, Dublin, Ireland. Poster.

11. Stefanelli P, Fazio C, Fedele G, Spensieri F, Ausiello CM, Mastrantonio P. A natural pertactin deficient strain of Bordetella pertussis shows improved entry in human monocyte-derived dendritic cells. New Microbiol. 2009;32(2):159-66. PMID: 19579693

12. Zeddeman A, van Gent M, Heuvelman CJ, van der Heide HG, Bart MJ, Advani A, et al. Investigations into the emergence of pertactin-deficient Bordetella pertussis isolates in six European countries, 1996 to 2012. Euro Surveill. 2014;19(33):20881. https://doi.org/10.2807/1560-7917. ES2014.19.33.20881 PMID: 25166348

13. Lam C, Octavia S, Ricafort L, Sintchenko V, Gilbert GL, Wood N, et al. Rapid increase in pertactin-deficient Bordetella pertussis isolates, Australia. Emerg Infect Dis. 2014;20(4):626-33. https://doi.org/10.3201/eid2004.131478 PMID: 24655754

14. Williams MM, Sen K, Weigand MR, Skoff TH, Cunningham VA, Halse TA, et al. CDC Pertussis Working Group. Bordetella pertussis Strain Lacking Pertactin and Pertussis Toxin. Emerg Infect Dis. 2016;22(2):319-22. https://doi.org/10.3201/ eid2202.151332 PMID: 26812174

15. Bart MJ, van der Heide HG, Zeddeman A, Heuvelman K, van Gent M, Mooi FR. Complete Genome Sequences of 11
Bordetella pertussis Strains Representing the Pandemic ptxP Lineage. Genome Announc. 2015;3(6):e01394-15. https://doi. org/10.1128/genomeA.01394-15 PMID: 26607899

16. Hegerle N, Paris AS, Brun D, Dore G, Njamkepo E, Guillot S, et al. Evolution of French Bordetella pertussis and Bordetella parapertussis isolates: increase of Bordetellae not expressing pertactin. Clin Microbiol Infect. 2012;18(9):E340-6. https:// doi.org/10.1111/j.1469-0691.2012.03925.x PMID: 22717007

17. European Centre for Disease Prevention and Control (ECDC). Vaccine Schedule - Pertussis. [Accessed 4 Apr 2017] Available from: http://vaccine- schedule.ecdc.europa.eu/pages/ scheduler.aspx

18. van Gent M, Heuvelman CJ, van der Heide HG, Hallander HO, Advani A, Guiso N, et al. Analysis of Bordetella pertussis clinical isolates circulating in European countries during the period 1998-2012. Eur J Clin Microbiol Infect Dis. 2015;34(4):821-30. https://doi.org/10.1007/s10096-014-22972 PMID: 25527446

19. Advani A, Hallander HO, Dalby T, Krogfelt KA, Guiso N, Njamkepo E, et al. Pulsed-field gel electrophoresis analysis of Bordetella pertussis isolates circulating in Europe from 1998 to 2009. J Clin Microbiol. 2013;51(2):422-8. https://doi. org/10.1128/JCM.02036-12 PMID: 23175253

20. Barkoff AM, Gröndahl-Yli-Hannuksela K, He Q. Seroprevalence studies of pertussis: what have we learned from different immunized populations. Pathog Dis. 2015;73(7):ftv050. https://doi.org/10.1093/femspd/ftv050 PMID: 26208655

21. Barkoff AM, Guiso N, Guillot S, Xing D, Markey K, Berbers $\mathrm{G}$, et al. A rapid ELISA-based method for screening Bordetella pertussis strain production of antigens included in current acellular pertussis vaccines. J Immunol Methods. 2014;408:142-8. https://doi.org/10.1016/j.jim.2014.06.001 PMID: 24925807

22. Heikkinen E, Xing DK, Olander RM, Hytönen J, Viljanen MK, Mertsola J, et al. Bordetella pertussis isolates in Finland: serotype and fimbrial expression. BMC Microbiol. 2008;8(1):162. https://doi.org/10.1186/1471-2180-8-162 PMID: 18816412

23. Mooi FR, van Oirschot $\mathrm{H}$, Heuvelman $\mathrm{K}$, van der Heide HG, Gaastra W, Willems RJ. Polymorphism in the Bordetella pertussis virulence factors P.69/pertactin and pertussis toxin in The Netherlands: temporal trends and evidence for vaccinedriven evolution. Infect Immun. 1998;66(2):670-5. PMID: 9453625

24. Parkhill J, Sebaihia M, Preston A, Murphy LD, Thomson $\mathrm{N}$, Harris DE, et al. Comparative analysis of the genome sequences of Bordetella pertussis, Bordetella parapertussis and Bordetella bronchiseptica. Nat Genet. 2003;35(1):32-40. https://doi.org/10.1038/ng1227 PMID: 12910271

25. Hallander $\mathrm{H}$, Advani A, Riffelmann M, von König $\mathrm{CH}$, Caro V, Guiso N, et al. Bordetella pertussis strains circulating in Europe in 1999 to 2004 as determined by pulsed-field gel electrophoresis. J Clin Microbiol. 2007;45(10):3257-62. https:// doi.org/10.1128/JCM.00864-07 PMID: 17699646

26. Thierry-Carstensen B, Dalby T, Stevner MA, Robbins JB, Schneerson R, Trollfors B. Experience with monocomponent acellular pertussis combination vaccines for infants, children, adolescents and adults--a review of safety, immunogenicity, efficacy and effectiveness studies and 15 years of field experience. Vaccine. 2013;31(45):5178-91. https://doi. org/10.1016/j.vaccine.2013.08.034 PMID: 23994021

27. Safarchi A, Octavia S, Luu LD, Tay CY, Sintchenko V, Wood N, et al. Pertactin negative Bordetella pertussis demonstrates higher fitness under vaccine selection pressure in a mixed infection model. Vaccine. 2015;33(46):6277-81. https://doi. org/10.1016/j.vaccine.2015.09.064 PMID: 26432908

28. Pawloski LC, Queenan AM, Cassiday PK, Lynch AS, Harrison MJ, Shang W, et al. Prevalence and molecular characterization of pertactin-deficient Bordetella pertussis in the United States. Clin Vaccine Immunol. 2014;21(2):119-25. https://doi. org/10.1128/CVI.00717-13 PMID: 24256623

29. Hegerle N, Guiso N. Bordetella pertussis and pertactindeficient clinical isolates: lessons for pertussis vaccines. Expert Rev Vaccines. 2014;13(9):1135-46. https://doi.org/10.15 86/14760584.2014.932254 PMID: 24953157

30. Otsuka N, Han HJ, Toyoizumi-Ajisaka H, Nakamura Y, Arakawa $\mathrm{Y}$, Shibayama K, et al. Prevalence and genetic characterization of pertactin-deficient Bordetella pertussis in Japan. PLoS One. 2012;7(2):e31985. https://doi.org/10.1371/journal. pone.0031985 PMID: 22348138

31. Hiramatsu Y, Miyaji Y, Otsuka N, Arakawa Y, Shibayama K, Kamachi K. Significant Decrease in Pertactin-Deficient Bordetella pertussis Isolates, Japan. Emerg Infect Dis. 2017;23(4):699-701. https://doi.org/10.3201/eid2304.161575 PMID: 28322702 
32. Miyaji Y, Otsuka N, Toyoizumi-Ajisaka H, Shibayama K,

Kamachi K. Genetic analysis of Bordetella pertussis isolates

from the 2008-2010 pertussis epidemic in Japan. PLoS

One. 2013;8(10):e77165. https://doi.org/10.1371/journal.

pone.0077165 PMID: 24124606

33. Zöldi V, Sane J, Nohynek H, Virkki M, Hannila-Handelberg T,

Mertsola J. Decreased incidence of pertussis in young adults after the introduction of booster vaccine in military conscripts: Epidemiological analyses of pertussis in Finland, 1995-2015.

Vaccine. 2017:35(39):5249-55. https://doi.org/10.1016/i. vaccine.2017.08.008 PMID: 28823620

\section{License and copyright}

This is an open-access article distributed under the terms of the Creative Commons Attribution (CC BY 4.0) Licence. You may share and adapt the material, but must give appropriate credit to the source, provide a link to the licence, and indicate if changes were made.

This article is copyright of the authors or their affiliated institutions, 2019. 